\title{
Evaluation of Biomedical Waste Management Practices in a Tertiary Health Care Institute in Telangana, India
}

\author{
C.M. Swathi, K. Shirisha*, Shyamala, Aruna Sunder and Achut Rao \\ Department of Microbiology, Mallareddy Medical College for Women \& Mallareddy \\ Narayana Multispeciality Hospital, Hyderabad, Telangana, India \\ *Corresponding author
}

\section{A B S T R A C T}

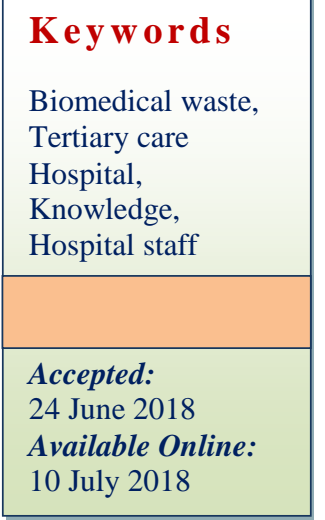

\section{Keywords}

Biomedical waste, Tertiary care Hospital, Knowledge, Hospital staff

\section{Introduction}

Biomedical waste (BMW) is the waste generated during diagnosis, treatment or immunization of human beings or animals, or in research activities pertaining thereto, or in the production and testing of biologicals, and is contaminated with human fluids (Government of India; BMW rules 1998). The Biomedical waste carries a higher potential for infection and injury than any other type of waste (Ismail et al., 2013).
Expansion of health-care facilities as well as the recent trends of using plastic disposables and increase in medical and surgical interventions has led to unprecedented burden of biomedical waste (BMW). Unregulated BMW management (BMWM) has posed a grave threat not only to human health and safety but also to environment for the current and future generations (Chartier et al., 2014).

A prior study estimated that about half of world's population is at risk from hazards of improper BMWM either through impact at 
work in the environment or impact on public health. The public health threat due to improper BMWM has been reported worldwide (Harhay et al., 2009). Of note are the incidence of hepatitis B virus (HBV) outbreak (240 infected) at Gujarat, India, in 2009 and infectious injuries to scavengers due to BMW generated in mass vaccinations (1.6 million) in Afghanistan (Chartier et al., 2014).

A nationwide survey performed by International Clinical Epidemiology Network in 25 districts across 20 states highlighted that only two big cities in India, Chennai and Mumbai, had comparatively better system for BMWM. Improper pre-treatment of BMW at source and improper terminal disposal were the major challenges observed. It was observed that around $82 \%$ of primary, $60 \%$ of secondary and $54 \%$ of tertiary care health facilities were in the red category, i.e., the absence of a credible BMWM in place or ones requiring major improvement (IPEN Study Group,2014).

According to the studies conducted by the World Health Organization (WHO) in 22 developing countries the proportion of healthcare facility $(\mathrm{HCF})$ that do not use proper waste disposal methods range from $18 \%$ to 64\%(WHO Factsheet No. 253; 2011).In India, annually about 0.33 million tons of BMW is generated and rate ranges from 0.5 to $2.0 \mathrm{~kg}$ per bed per day (Mathur et al., 2011).

In some hospital there is no proper training of the employees in hazardous waste management. This indicates the lack of even basic awareness among hospital personnel regarding safe disposal of Bio- Medical waste. Keeping in view the above scenario, the present study has been undertaken to assess the knowledge regarding different aspects of Bio- medical waste amongst doctors, nurses, laboratory technicians, and sanitary staff of Mallareddy Narayana Multispeciality
Hospital, a tertiary care hospital in Suraram, Hyderabad, Telangana.

\section{Materials and Methods}

The present study is a cross sectional study carried out to assess and improve the knowledge of paramedical staff of Mallareddy Medical College for Women, suraram. The study group comprised of healthcare personnel who included doctors, nurses, laboratory technicians and Class IV employees working in the institution. The study subjects consisted of 174 respondents: 40 nurses, 20 technicians, 20 housekeeping and94 Doctors.

The training was conducted in several phases, for this a schedule was prepared in advance keeping in mind the various categories of staff in the hospital and a date was fixed for the training of the respective staff in the month of May 2018. Each batch was given training by the Microbiology department on the different aspects of biomedical waste management of the hospital. A pre-designed proforma was used for data collection. Study proforma consisted of twenty multiple choice questions relating to Biomedical waste management i.e. hazards associated with biomedical waste, methods for prevention of hazards, colour coding, waste segregation.

The proforma was filled by study subjects before the start of the training and the same set of proforma was given to them at the end of the training session. Thus, the first was taken as pre-test and latter as a post-test. Each correct response was assigned one mark. Self made scoring system was used to categorize the participants as having good, average and poor knowledge regarding the subject. Participants scoring more than 15 were graded as Good, between 10-15 as Average and those who scored less than 10 were categorized as having Poor knowledge. 


\section{Results and Discussion}

Table 1 (shown below) shows result percentage of the 94 Junior Doctors who participated in the study during the pre-test and post-test assessment. In the pre-test session, majority (47\%) of Junior Doctors scored between 10 and 15 (average) and only42.5\% scored more than 15 (good). The scoring level went high in post-test assessment as $76.5 \%$ of Junior Doctors were found to score more than 75 percent.

Table 2 shows the comparative analysis of pre-test and post-test assessment of the nursing staff. Out of 40 nursing staff, Majority $(60 \%)$ of the nursing staff during preassessment were found to score $<10$ marks while remarkable improvement was observed during the course of post assessment as evidenced by $55 \%$ scoring more than 15 as against $7.5 \%$ who scored more than 8 during pre-test assessment
Table 3 shows result in percentage of the 20 technicians participated in the study of which $40 \%$ of the technicians during pre-test assessment were found to score more than 15 . In the post test assessment, 55\% of the technicians scored more than 15 .

Table 4 shows result in percentage of the 20 House keeping staff participated in the study of which $5 \%$ of Housekeeping staff during pre-test assessment were found to score more than 15 . In the post test assessment, only $10 \%$ Housekeeping staff of the scored more than 15.

Analysis of data revealed that on all counts, doctors, nurses, and laboratory technicians have better knowledge than sanitary staff regarding biomedical waste management. Knowledge regarding the colour coding and waste segregation at source was found to be better among nurses and laboratory staff as compared to doctors.

Table.1 Pre and post-test assessment of junior doctors

\begin{tabular}{|l|c|c|c|c|}
\hline Marks & Pre-test (n=94) & Percentage (\%) & Post-test (n=94) & Percentage (\%) \\
\hline$<\mathbf{1 0}$ & 10 & $10.5 \%$ & 02 & $2.2 \%$ \\
\hline $\mathbf{1 0 - 1 5}$ & 44 & $47 \%$ & 20 & 21.3 \\
\hline $\mathbf{1 5}$ & 40 & $42.5 \%$ & 72 & $76.5 \%$ \\
\hline Total & 94 & $100 \%$ & 94 & $100 \%$ \\
\hline
\end{tabular}

Table.2 Pre and post-test assessment of nurses

\begin{tabular}{|l|c|c|c|c|}
\hline Marks & Pre-test $(\mathbf{n}=\mathbf{4 0})$ & Percentage (\%) & Post-test $(\mathbf{n}=\mathbf{4 0})$ & Percentage (\%) \\
\hline$<\mathbf{1 0}$ & 24 & $60 \%$ & 5 & $12.5 \%$ \\
\hline $\mathbf{1 0}-15$ & 13 & $32.5 \%$ & 18 & $45 \%$ \\
\hline$>\mathbf{1 5}$ & 03 & $7.5 \%$ & 27 & $67.5 \%$ \\
\hline Total & 40 & $100 \%$ & 40 & $100 \%$ \\
\hline
\end{tabular}

Table.3 Pre and post-test assessment of lab-technicians

\begin{tabular}{|l|c|c|c|c|}
\hline Marks & Pre-test (n=20) & Percentage (\%) & Post-test (n=20) & Percentage (\%) \\
\hline $\mathbf{1 0}$ & 02 & $10 \%$ & 01 & $5 \%$ \\
\hline $\mathbf{1 0 - 1 5}$ & 10 & $50 \%$ & 08 & $40 \%$ \\
\hline$>\mathbf{1 5}$ & 08 & $40 \%$ & 11 & $55 \%$ \\
\hline Total & 20 & $100 \%$ & 20 & $100 \%$ \\
\hline
\end{tabular}


Table.4 Pre and post-test assessment of housekeeping staff

\begin{tabular}{|l|c|c|c|c|}
\hline Marks & Pre-test $(\mathbf{n = 2 0})$ & Percentage (\%) & Post-test $(\mathbf{n = 2 0})$ & Percentage (\%) \\
\hline $\mathbf{1 0}$ & 12 & $60 \%$ & 07 & $35 \%$ \\
\hline $\mathbf{1 0 - 1 5}$ & 07 & $35 \%$ & 11 & $55 \%$ \\
\hline$>\mathbf{1 5}$ & 01 & $5 \%$ & 02 & $10 \%$ \\
\hline Total & 20 & $100 \%$ & 20 & $100 \%$ \\
\hline
\end{tabular}

The study was conducted on predesigned and pretested questionnaire and a cross-sectional study design was selected as a similar design which was adopted in other studies (Pandit et al., 2008; Kishore et al., 2000; Verma et al., 2008). Knowledge about biomedical waste management rules among the technically qualified personnel like the doctors, nurses, and laboratory staff was high but was low among the sanitary staff; this was similar to the findings from other studies (Pandit et al., 2008; Saini et al., 2005). Similarly, knowledge about colour coding of containers, and waste segregation which itself is probably the most important pivotal point and crucial for further waste management, was also found to be better among the technically qualified staff as compared to that of the sanitary staff. Low level of knowledge is mainly attributed to poor training facilities and also to relatively low educational level of the sanitary staff. Training of both the technical staff and the non-technical staff is critical for the proper and appropriate management of biomedical waste (Pandit et al., 2008; Kishore et al., 2000).

Conclusion and recommendations are as follows:

Concluding from the results, the importance of training regarding biomedical waste management cannot be overemphasized; lack of proper and complete knowledge about biomedical waste management impacts practices of appropriate waste disposal.
Following recommendations are proposed:

Strict implementation of biomedical waste management rules is the need of the hour,

It should be made compulsory for healthcare facilities to get their healthcare personnel trained from accredited training centers. These training sessions should not become merely a one-time activity but should be a continuous process depending upon the patient input in different healthcare facilities, Training of sanitary staff should be specially emphasized.

\section{References}

Chartier Y, Emmanuel J, Pieper U, Prüss A, Rushbrook P, Stringer R, et al., editors. Safe Management of Wastes from Health-Care Activities. 2nd ed. Geneva, Switzerland: WHO Blue Book; 2014

Government of India; Biomedical Waste (Management and Handling) Rules 1998. Extraordinary, Part II, Section 3, Subsection (ii). The gazette of India, No. 460, 27 Jul 1998

Harhay MO, Halpern SD, Harhay JS, Olliaro PL. Health care waste management: A neglected and growing public health problem worldwide. Trop Med Int Health 2009; 14:1414-7.

INCLEN Program Evaluation Network (IPEN) Study Group, New Delhi, India. Bio-medical waste management: Situational analysis and predictors of performances in 25 districts across 20 
Indian States. Indian J Med Res 2014; 139: 141-53.

Ismail IM, Kulkarni AG, Kamble SV, Borker SA, Rekha R, Amruth M; Knowledge, attitude and practice about biomedical waste management among personnel of a tertiary health care institute in Dakshina Kannada, Karnataka. Al Ameen J Med Sci., 2013; 6(4): 376-380.

Kishore J, Goel P, Sagar B, Joshi TK. Awareness about biomedical waste management and infection control among dentists of a teaching hospital in New Delhi, India. Indian J Dent Res 2000; 11: 157-61.

Mathur V, Dwivedi S, Hassan M, Misra R. Knowledge, attitude, and practices about biomedical waste management among healthcare personnel: A crosssectional study. Indian J Community Med 2011; 36: 143-5.

Pandit NB, Mehta HK, Kartha GP,
Choudhary SK. Management of biomedical waste: Awareness and practices in a district of Gujarat. Indian J Public Health 2005; 49: 2457.

Saini S, Nagarajan SS, Sarma RK. Knowledge; Attitude and Practices of Bio-Medical Waste Management Amongst Staff of a Tertiary Level Hospital in India. J AcadHospAdm., $2005 ; 17: 2$.

Verma LK, Mani S, Sinha N, Rana S. Biomedical waste management in nursing homes and smaller hospitals in Delhi. Waste Manage Res 2008; 28: 2723-34.

World Health Organization (WHO). Wastes from Health-Care Activities. Factsheet No. 253; November, 2011. Availablefrom:http://www.who.int/me diacentre/factsheets/fs253/en. (Last accessed on 2017 May 3).

\section{How to cite this article:}

Swathi, C.M., K. Shirisha, Shyamala, Aruna Sunder and Achut Rao. 2018. Evaluation of Biomedical Waste Management Practices in a Tertiary Health Care Institute in Telangana, India. Int.J.Curr.Microbiol.App.Sci. 7(07): 3226-3230. doi: https://doi.org/10.20546/ijcmas.2018.707.376 